\title{
Numerical analysis of the effects of downhole dynamic conditions on formation testing while drilling
}

\author{
DI Dejia ${ }^{1,2}$, TAO Guo ${ }^{1,3}$, WANG Bing ${ }^{1 *}$, CHEN Xu ${ }^{1}$ and SUN Jiming ${ }^{1}$ \\ ${ }^{1}$ State Key Laboratory of Petroleum Resources and Prospecting, China University of Petroleum, Beijing 102249, China \\ ${ }^{2}$ SINOPEC Research Institute of Petroleum Engineering, Beijing 100101, China \\ ${ }^{3}$ Departments of Petroleum Geosciences \& Engineering, The Petroleum Institute, Abu Dhabi, UAE
}

(C) China University of Petroleum (Beijing) and Springer-Verlag Berlin Heidelberg 2014

\begin{abstract}
Formation testing while drilling is an innovative technique that is replacing conventional pressure testing in which the fluid sampling is conducted in a relatively short time following the drilling. At this time, mud invasion has just started, mudcake has not formed entirely and the formation pressure is not stable. Therefore, it is important to study the influence of the downhole dynamic environment on pressure testing and fluid sampling. This paper applies an oil-water two phase finite element model to study the influence of mudcake quality and mud filtrate invasion on supercharge pressure, pretest and sampling in the reservoirs of different permeability. However, the study is only for the cases with water based mud in the wellbore. The results illustrate that the mudcake quality has a significant influence on the supercharge pressure and fluid sampling, while the level of mud filtrate invasion has a strong impact on pressure testing and sampling. In addition, in-situ formation pressure testing is more difficult in low permeability reservoirs as the mud filtrate invasion is deeper and therefore degrades the quality of fluid sampling. Finally, a field example from an oil field on the Alaskan North Slope is presented to validate the numerical studies of the effects of downhole dynamic conditions on formation testing while drilling.
\end{abstract}

Key words: Formation testing while drilling, formation supercharge, pressure testing, fluid sampling, finite element method, mudcake, filtrate invasion

\section{Introduction}

Formation testing while drilling (FTWD), based on drill stem testing (DST) and wireline formation testing (WFT), is an innovation of logging while drilling (LWD). FTWD can not only carry out the function of WFT, such as fluid sampling, pressure and temperature testing, but also can be used for detecting annular pressure and original formation pressure in real time to optimize mud formulation and improve drilling safety. FTWD is suitable for the formation testing of extended reach wells and horizontal wells and hence can reduce the drilling time and cost over WFT (Hou et al, 2005; Lee et al, 2004; Finneran et al, 2005; Pop et al, 2005; Proett et al, 2003; 2004; 2010; 2011; Seifert et al, 2005; Fey et al, 2011; Masoud et al, 2009; Di et al, 2012a; 2012b; 2012 c). So far only major international oil service companies have developed their own FTWD tools, such as StethoScope developed by Schlumberger, TesTrak developed by Baker Hughes and Geo-Tap developed by Halliburton. In China, few national companies have been developing the technology

*Corresponding author. email: wangbing@cup.edu.cn

Received August 15, 2013 during the National 11th Five-Year Plan and the subsequent National 12th Five-Year Plan. The representational tools are SDC-1 developed by Daqing Drilling Engineering Technology Research Institute and CPWD developed by CNPC Drilling Research Institute (Ren and Ma, 2005; Su and Dou, 2005; Yang and Tian, 2005; Zhang et al, 2006; Li et al, 2008; Wang et al, 2009; Liu et al, 2010; Zhao et al, 2011).

FTWD starts fluid sampling and pressure testing after the drill bit breaks the formation for a short time. The mud invasion has just started but the mudcake has not been formed entirely and the formation pressure is not stable during the procedure. The complicated downhole environment is quite different from that of WFT. Therefore, it is important to consider the influence of the downhole dynamic environment on the pressure testing and sampling. Lee et al (1998) and Sarkar et al (1998) analyzed the influence of mudcake quality, depth of mud filtrate invasion and formation anisotropy on fluid sampling of WFT using the finite element method. However, the effects of mudcake parameters and filtrate invasion on formation supercharge have not been considered. Usually, the mud hydrostatic pressure is set higher than the original formation pressure to ensure drilling safety. Consequently a certain amount of filtrate invasion occurs 
and this in turn leads to a higher formation pressure near the wellbore than the original formation pressure, especially in low permeability formations. This so called supercharge pressure is shown to be a product of the apparent overbalance pressure between the invasion zone and the original formation. On the other hand, the mudcake can also isolate the wellbore from the original formation and prevent the mud filtrate invasion. Therefore, the mudcake permeability has a direct influence on the formation pressure near the wellbore.

A simple equation was formulated for estimating the supercharge pressure, assuming that a steady condition is reached at the time when the FTWD measurements are made (Proett et al, 2011). In the steady state, single-phase flow of filtrate through the mudcake is expressed by Darcy's law as follows

$$
q_{\mathrm{mc}}=\frac{2 \pi k_{\mathrm{mc}} h}{\mu} \frac{\left(p_{\mathrm{w}}-p_{\mathrm{s}}\right)}{\ln \frac{r_{\mathrm{s}}}{r_{\mathrm{w}}}}
$$

where $r_{\mathrm{s}}=r_{\mathrm{w}}+l_{\mathrm{mc}} ; q_{\mathrm{mc}}$ is the filtrate flow rate through the mudcake, $\mathrm{mL} / \mathrm{s} ; k_{\mathrm{mc}}$ is the mudcake permeability, $\mathrm{mD} ; \mu$ is the filtrate viscosity, $\mathrm{mPa} \cdot \mathrm{s} ; h$ is the formation thickness, $\mathrm{m}$; $p_{\mathrm{w}}$ is the liquid column hydrostatic pressure, $\mathrm{psi} ; p_{\mathrm{s}}$ is the pressure at the mudcake/formation interface, $\mathrm{psi} ; r_{\mathrm{w}}$ is the wellbore radius, $\mathrm{cm} ; l_{\mathrm{mc}}$ is the mudcake thickness, $\mathrm{cm}$.

Similarly, the steady state flow invading through the formation is expressed as

$$
q_{\mathrm{f}}=\frac{2 \pi k_{\mathrm{f}} h}{\mu} \frac{\left(p_{\mathrm{s}}-p_{\mathrm{f}}\right)}{\ln \frac{r_{\mathrm{f}}}{r_{\mathrm{s}}}}
$$

where $r_{\mathrm{f}}$ is the radial distance of supercharging, $\mathrm{cm} ; q_{\mathrm{f}}$ is the filtrate flow rate through the formation, $\mathrm{mL} / \mathrm{s} ; p_{\mathrm{f}}$ is the formation pressure, $\mathrm{psi} ; k_{\mathrm{f}}$ is the formation permeability, $\mathrm{mD}$. Under steady conditions these two flow rates are equal. Hence,

$$
q_{\mathrm{mc}}=q_{\mathrm{f}} \text { or } p_{\mathrm{f}}=p_{\mathrm{s}}-\Delta p_{\mathrm{sc}}
$$

where $\Delta p_{\mathrm{sc}}$ is the supercharge pressure and is defined as

$$
\Delta p_{\mathrm{sc}}=\left(p_{\mathrm{w}}-p_{\mathrm{s}}\right) \frac{k_{\mathrm{mc}}}{k_{\mathrm{f}}}\left[\frac{\ln \frac{r_{\mathrm{f}}}{r_{\mathrm{w}}+l_{\mathrm{mc}}}}{\ln \frac{r_{\mathrm{w}}+l_{\mathrm{mc}}}{r_{\mathrm{w}}}}\right]
$$

The above equation indicates that the supercharge pressure is related to the apparent overbalance pressure, the mudcaketo-formation permeability ratio, and the invasion factor.

As the formation testing procedure involves interactions of the downhole tool probe, borehole and formation fluids and solid rocks, as well as mudcake, it possess a typical fluid flow problem in a domain of complex geometry. Finite element methods (FEM) have shown the ability to quantitatively analyze the relationship between the formation pressure and parameters in such a complicated situation. In order to study the effect of the downhole dynamic environment on the pressure testing and fluid sampling, we developed a FEM simulator to study the effects of mudcakes, invasion depth, formation permeability and differential fluid pressure on the pressure testing and fluid sampling.

\section{Mathematical model}

The process of formation testing while drilling is actually a process of seepage. The water saturation near the wellbore is different from the water saturation of the original formation, and there inevitably exists an oil-water phase near the probe in the process of pumping fluid. Therefore, the mathematical treatment of formation testing is to solve the problem of oilwater two phase flow in the porous medium. According to the principle of the mechanics of fluid flow in porous media, the fundamental derivative equations of oil-water two phase flow in the formation can be derived as follows (Zhou et al, 2003; 2007; Gu et al, 2005a; 2005b; 2007; Yi et al, 1997):

$$
\left\{\begin{array}{l}
\nabla \cdot\left[\left(\frac{k \cdot K_{\mathrm{ro}}\left(S_{\mathrm{w}}\right)}{\mu_{\mathrm{o}}}+\frac{k \cdot K_{\mathrm{rw}}\left(S_{\mathrm{w}}\right)}{\mu_{\mathrm{w}}}\right) \nabla P_{\mathrm{o}}\right]-\nabla \cdot\left[\frac{k \cdot K_{\mathrm{rw}}\left(S_{\mathrm{w}}\right)}{\mu_{\mathrm{w}}} \nabla P_{\mathrm{c}}\left(S_{\mathrm{w}}\right)\right]=\varphi C_{\mathrm{fw}}\left(S_{\mathrm{w}}\right) \frac{\partial P_{\mathrm{o}}}{\partial t} \\
\nabla \cdot\left[\frac{k \cdot K_{\mathrm{ro}}\left(S_{\mathrm{w}}\right)}{\mu_{\mathrm{o}}}\left(\nabla P_{\mathrm{o}}\right)\right]=\varphi \frac{\partial S_{\mathrm{o}}}{\partial t}+\varphi S_{\mathrm{o}} C_{\mathrm{fo}} \frac{\partial P_{\mathrm{o}}}{\partial t} \\
\left.P_{\mathrm{o}}\right|_{t=0}=\left.P\right|_{l \rightarrow \infty}=P_{\mathrm{oi}} \\
-\left.k\left(\left(\frac{K_{\mathrm{ro}}\left(S_{\mathrm{w}}\right)}{\mu_{\mathrm{o}}}+\frac{K_{\mathrm{rw}}\left(S_{\mathrm{w}}\right)}{\mu_{\mathrm{w}}}\right) \nabla P_{\mathrm{o}}-\frac{K_{\mathrm{rw}}\left(S_{\mathrm{w}}\right)}{\mu_{\mathrm{w}}} \nabla P_{\mathrm{c}}\left(S_{\mathrm{w}}\right)\right) \cdot \pi r_{\mathrm{s}}^{2}\right|_{\text {probe }}=q
\end{array}\right.
$$

where $k$ is the absolute permeability of the media, $\mathrm{mD}$; $K_{\text {rw }}$ and $K_{\text {ro }}$ are the relative permeability to water and oil, respectively; $\mu_{\mathrm{w}}$ and $\mu_{\mathrm{o}}$ are the water and oil viscosity respectively, $\mathrm{mPa} \cdot \mathrm{s} ; P_{\mathrm{o}}$ and $P_{\mathrm{w}}$ are the oil and water pressures respectively, psi; $P_{\mathrm{c}}$ is the capillary force, psi; $S_{\mathrm{w}}$ is the water saturation; $S_{0}$ is the oil phase saturation; $\varphi$ is the formation porosity; $C_{\mathrm{fw}}$ is the compression coefficient of the water phase; $C_{\mathrm{fo}}$ is the compression coefficient of the oil phase; $q$ is the flow rate that probe sucks fluid, $\mathrm{mL} / \mathrm{s} ; r_{\mathrm{s}}$ is the radius of probe, $\mathrm{cm}$.

We can obtain relative permeability curves from the data of the numerical reservoir simulation. The relative permeability equations (Eqs. (6)-(8)) were applied in the model. 
Water phase:

$$
K_{\mathrm{rw}}\left(S_{\mathrm{w}}\right)= \begin{cases}0.0 & S_{\mathrm{w}}<0.21 \\ 1.4437 S_{\mathrm{w}}^{2}-0.4758 S_{\mathrm{w}}+0.00434 & 0.81<S_{\mathrm{w}}<0.21 \\ K_{\mathrm{rmax}} & S_{\mathrm{w}}>0.81\end{cases}
$$

Oil phase:

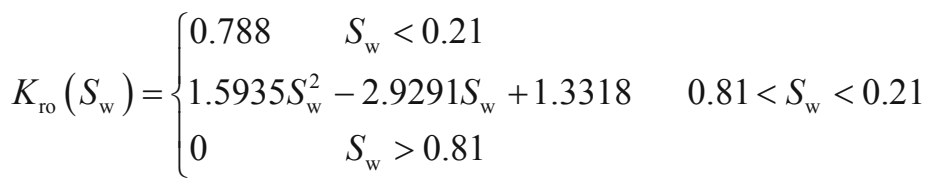

Capillary pressure equation:

$$
P_{\mathrm{c}}\left(S_{\mathrm{w}}\right)=55080.4\left(1-S_{\mathrm{w}}\right)^{1.5}
$$

The pressure equation in the mathematical model is an elliptic equation (Eq. (9)), which can be solved by the Garlerkin method,

$$
\begin{aligned}
& \iiint_{\Omega_{\mathrm{e}}}\left(\frac{k \cdot K_{\mathrm{rw}}}{\mu_{\mathrm{w}}}+\frac{k \cdot K_{\mathrm{ro}}}{\mu_{\mathrm{o}}}\right) \cdot \nabla P_{\mathrm{o}} \cdot \nabla N_{\mathrm{p} i} \cdot \mathrm{d} \Omega+\iiint_{\Omega_{\mathrm{e}}} \Phi \cdot C_{\mathrm{f}} \frac{\partial P}{\partial t} \cdot N_{\mathrm{p} i} \cdot \mathrm{d} \Omega_{\mathrm{e}} \\
& =\oiint_{\Gamma_{\mathrm{e}}}-\frac{q}{\pi r_{\mathrm{s}}^{2}} \cdot N_{\mathrm{p} i} \cdot \vec{n} \cdot \mathrm{d} \Gamma_{\mathrm{e}}+\iiint_{\Omega_{\mathrm{e}}} \frac{k \cdot K_{\mathrm{rw}}}{\mu_{\mathrm{w}}} \cdot \nabla P_{\mathrm{c}} \cdot \nabla N_{\mathrm{p} i} \cdot \mathrm{d} \Omega_{\mathrm{e}}
\end{aligned}
$$

where $i=1,2,3, \ldots, n ; \Omega_{\mathrm{e}}$ is unit area, $\vec{n}$ is the boundary normal; $N_{\mathrm{p} i}$ is the shape function of pressure equation.

For the saturation equation (Eq. (10)), the stiffness matrix in the finite element model established with the Garlerkin method is an ill-conditioned matrix, and the solved equations are pathological equations. Therefore, the least squares method is applied to establish the saturation equation of the finite element model, the equivalent integral weak form of the saturation field equations can be derived as

$$
\begin{aligned}
& \iiint_{\Omega}\left[\left(\phi+\phi C_{\mathrm{fo}} \frac{\partial P_{\mathrm{o}}}{\partial t} \cdot \mathrm{d} t\right) \cdot \mathbf{S}_{\mathrm{w} i}^{t+1}\right] \cdot\left[\left(\phi+\phi C_{\mathrm{fo}} \frac{\partial P_{\mathrm{o}}}{\partial t} \cdot \mathrm{d} t\right) \cdot\left(\mathbf{N}_{\mathrm{sw}}^{t+1}\right)^{\mathrm{T}}\right] \cdot \mathrm{d} \Omega \\
& =\iiint_{\Omega}\left[\phi S_{\mathrm{w}}^{t}+\phi C_{\mathrm{fo}} \frac{\partial P_{\mathrm{o}}}{\partial t} \cdot \mathrm{d} t-\nabla\left(\frac{k K_{\mathrm{ro}}}{\mu_{\mathrm{o}}} \nabla P_{\mathrm{o}}\right) \cdot \mathrm{d} t\right] \cdot\left[\left(\phi+\phi C_{\mathrm{fo}} \frac{\partial P_{\mathrm{o}}}{\partial t} \cdot \mathrm{d} t\right) \cdot\left(\mathbf{N}_{\mathrm{sw}}^{t+1}\right)^{\mathrm{T}}\right] \cdot \mathrm{d} \Omega
\end{aligned}
$$

where $i=1,2,3, \ldots, n ; N_{\mathrm{sw}}$ is the shape function of the saturation equation.

To check the validity of our finite element model, we first computed an example of 3D spherical flow in an isotropic formation, as an analytical solution for this case can be obtained too. A comparison of our numerical results with the analytical solution for the pressure profile at the probe is illustrated in Fig. 1, given the initial formation pressure of $5,000 \mathrm{psi}$, the formation permeability of $0.1 \mathrm{mD}$, the flow rate of the probe of $1 \mathrm{~mL} / \mathrm{s}$, the diameter of the probe of $1.27 \mathrm{~cm}$, and the formation permeability anisotropy in terms of $k_{\mathrm{z}} / k_{\mathrm{h}}$ of 1. It can be seen that there is almost no difference between the numerical and analytical solutions. The relative errors are less than $0.1 \%$. We thus believe that the finite element model is reliable and accurate enough. The tiny difference between the solutions could be caused by the geometrical simplification in the calculation of the analytical solution.

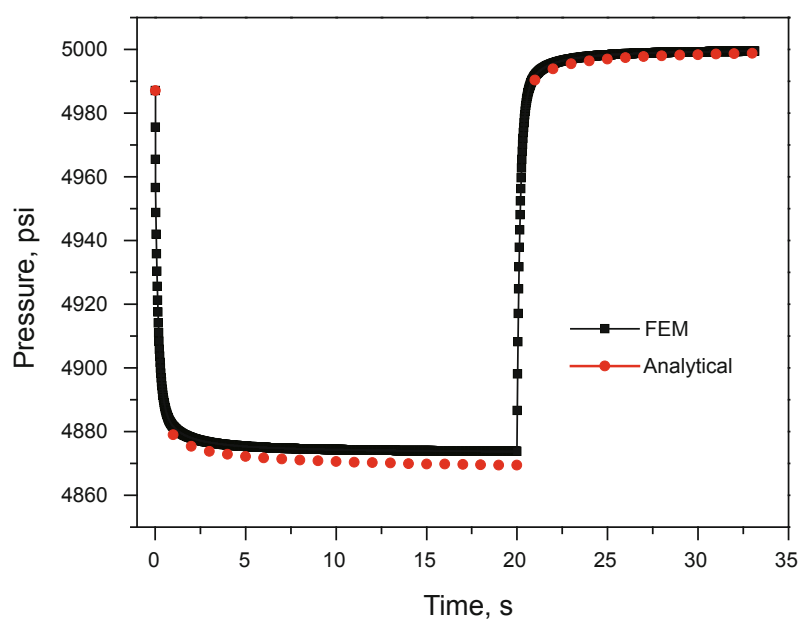

Fig. 1 A comparison of the analytical solution and the finite element calculation (single phase flow) 


\section{Modeling of changed formation pressure during mud invasion}

According to the field cases of downhole mud filtrate invasion and formation supercharging, we established a twodimensional axisymmetric model in the simulation software, as is shown in Fig. 2. In this model, the wellbore radius is 0.1 $\mathrm{m}$, the model is $10 \mathrm{~m}$ in radius and $5 \mathrm{~m}$ in thickness. We set up the wellbore, mudcake, mud filtrate and the formation in the model, and assigned the parameters to the different zones respectively according to the real conditions in the field (Table $1)$.

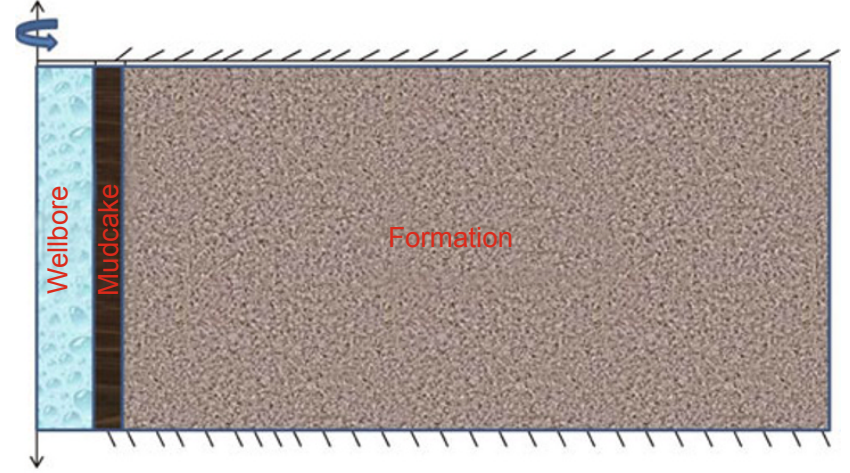

Fig. 2 Two-dimensional axisymmetric geometry for modeling downhole dynamic conditions

Table 1 The parameters for modeling downhole dynamic conditions

\begin{tabular}{cccccccc}
\hline & Porosity & $\begin{array}{c}\text { Permeability } \\
\mathrm{mD}\end{array}$ & $\begin{array}{c}\text { Fluid density } \\
\mathrm{kg} / \mathrm{m}^{3}\end{array}$ & $\begin{array}{c}\text { Fluid viscosity } \\
\mathrm{mPa} \cdot \mathrm{s}\end{array}$ & $\begin{array}{c}\text { Compressibility } \\
\mathrm{psi}^{-1}\end{array}$ & $\begin{array}{c}\text { Pressure } \\
\mathrm{psi}\end{array}$ & $\begin{array}{c}\text { Thickness } \\
\mathrm{cm}\end{array}$ \\
\hline Formation & 0.3 & 1.0 & 800 & 1.0 & $3 \times 10^{-6}$ & 5000 & - \\
Mudcake & 0.15 & $10^{-2}-10^{-5}$ & - & 1.0 & 0.1 & - & $0.5-2.0$ \\
Mud filtrate & - & - & 1000 & 0.5 & - & 5500 & - \\
\hline
\end{tabular}

\subsection{Effect of mudcake permeability on supercharge pressure}

We first investigated the effect of mudcake permeability on formation supercharge near the wellbore. Initially, assuming that the formation exposed to drilling fluids is completely sealed by the mudcake we started with these parameters: the mudcake thickness is $0.5 \mathrm{~cm}$, the formation permeability is $1 \mathrm{mD}$, the wellbore pressure is $5,500 \mathrm{psi}$, both the formation pressure and boundary pressure are 5,000 psi, and other parameters are listed in Table 1 . We then increased the mudcake permeability to calculate the formation supercharge step by step. Fig. 3 demonstrates these results from our FEM simulations. From this figure it can be seen that the formation supercharge pressure becomes higher when the mudcake permeability increases. The sandface pressure just behind the mudcake exceeds the formation pressure by 308 psi when the mudcake permeability is $0.01 \mathrm{mD}$. As the radial distance from the wellbore increases, the supercharging becomes weaker. At the distance of $5 \mathrm{~m}$ away from the wellbore, the wellbore pressure has little effect on the formation pressure even though the mudcake quality becomes very poor. As also shown in Fig. 3, as long as the mudcake permeability is less than $10^{-5} \mathrm{mD}$, the formation supercharge near the wellbore can be ignored. This is because the mudcake deposited on the wellbore face breaks the pressure connection between the wellbore and the formation and the drilling fluid does not flow into the formation, thus the wellbore hydrostatic pressure has little effect on the formation pressure around the wellbore.

FTWD is operated in a short time just after the drill bit breaks the formation. At this moment, some filtrate immediately invades the formation near the wellbore, but the mudcake has not formed entirely and hence the mudcake quality is poor. In such cases, wellbore supercharge may

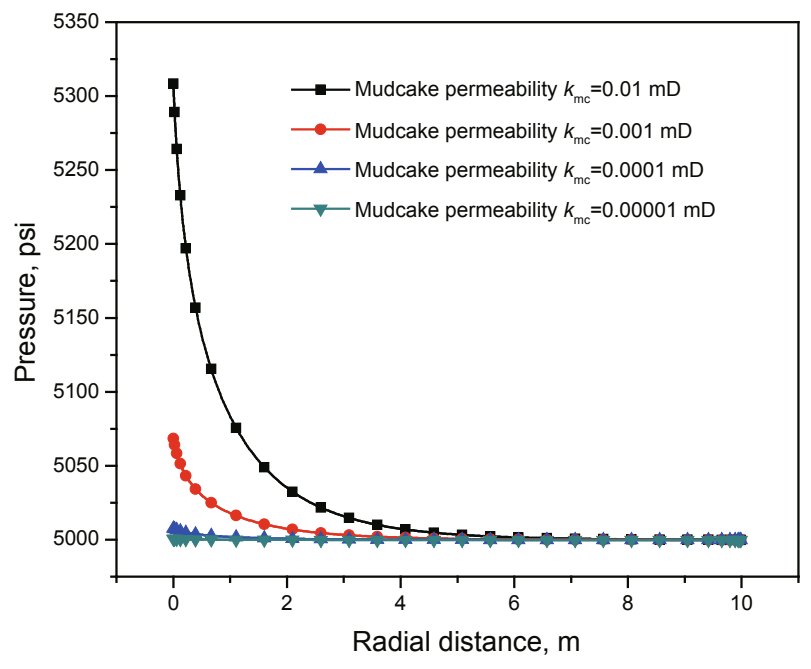

Fig. 3 The effect of mudcake permeability on supercharge pressure

occur near the wellbore and cause problems for FTWD. In field applications, the drilling and logging engineers have to do pressure testing at appropriate locations where the mudcake quality is good and the formation pressure is stable.

\subsection{Effect of mudcake thickness on supercharge pressure}

We subsequently investigated the influence of mudcake thickness on the formation supercharge pressure given that the formation and the mudcake have permeability of 1 and $10^{-3} \mathrm{mD}$, respectively. The other parameters of the model are listed in Table 1. These simulation results are shown in Fig. 4. It can be seen that the formation pressure is not affected by the mudcake thickness at the radial distance 
of $5 \mathrm{~m}$ away from the wellbore. However, the pressure at the borehole wall exceeds the formation pressure by $69 \mathrm{psi}$ when the mudcake thickness is $0.5 \mathrm{~cm}$. On the other hand, when the cake thickness is over $2.0 \mathrm{~cm}$, the supercharging is reduced substantially and can be ignored. This is because that the thicker mudcake formed on the wellbore face better isolates the drilling fluid in the wellbore from the formation, and hence the wellbore hydrostatic pressure has little effect on the formation pressure. Therefore, the location where the mudcake is sufficiently thick (in the case, over $2 \mathrm{~cm}$ ) should be considered as a candidate formation to be tested.

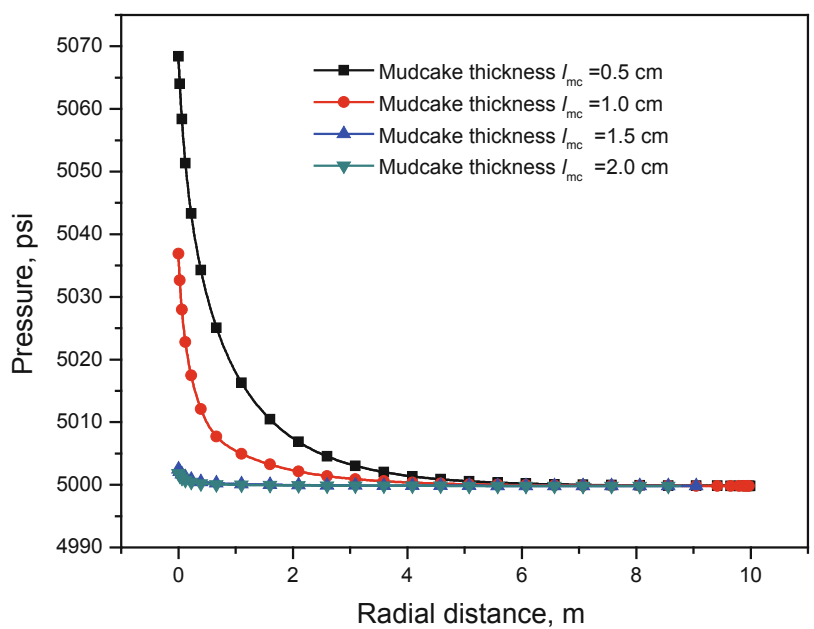

Fig. 4 The effect of mudcake thickness on supercharge pressure

\subsection{Effect of formation permeability on supercharge pressure}

To investigate the effect of formation permeability on formation supercharge, we analyzed the changes of formation pressure at different formation permeability when the mudcake thickness and permeability were set at $1 \mathrm{~cm}$ and $10^{-3}$ $\mathrm{mD}$. Fig. 5 shows that when the formation permeability is $0.1 \mathrm{mD}$, the formation pressure near the wellbore exceeds the original formation pressure by $225 \mathrm{psi}$. With an increase in the formation permeability, the supercharge pressure near the

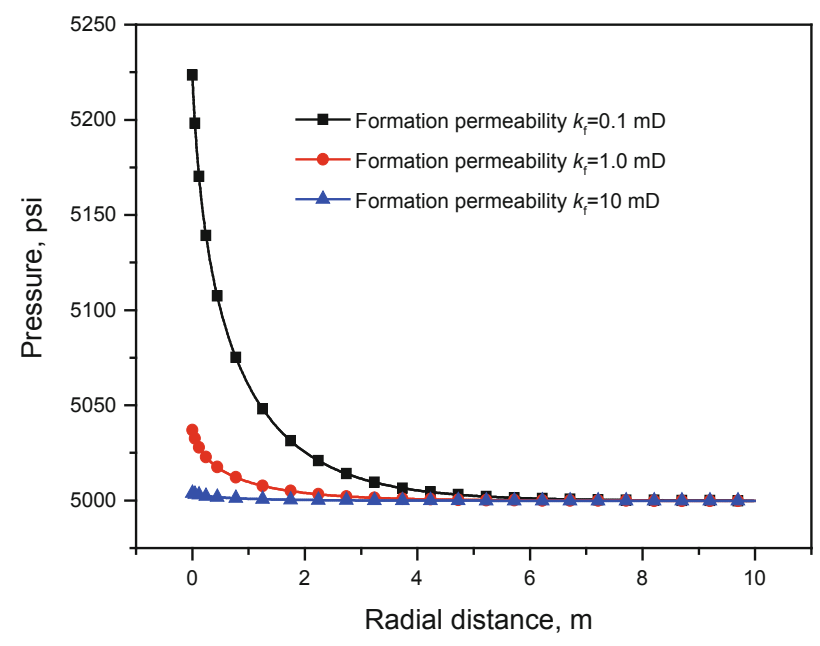

Fig. 5 The effect of formation permeability on supercharge pressure wellbore becomes lower. When the formation permeability increases to $10 \mathrm{mD}$, the supercharge pressure decreases substantially and can be ignored. According to the simulation results, the location for pressure testing should be selected where the formation of a permeability over $10 \mathrm{mD}$.

\subsection{Effect of mudcake permeability on fluid sampling}

Finally, we analyzed the influence of mudcake permeability on fluid sampling. The simulation parameters are as follows: The cake thickness is $1 \mathrm{~cm}$ and the pump rate used is $15 \mathrm{~mL} / \mathrm{s}$, the initial saturation of $100 \%$ filtrate at the wellbore is followed by a transitional zone of $15 \mathrm{~cm}$ to the non-invaded zone. The simulation results are shown in Fig. 6. It can be seen that the sampling quality will substantially degrade when the mudcake permeability is higher than $0.01 \mathrm{mD}$ due to continuous invasion of fresh mud filtrate. Therefore, the mudcake permeability should be considered in fluid sampling in field applications.

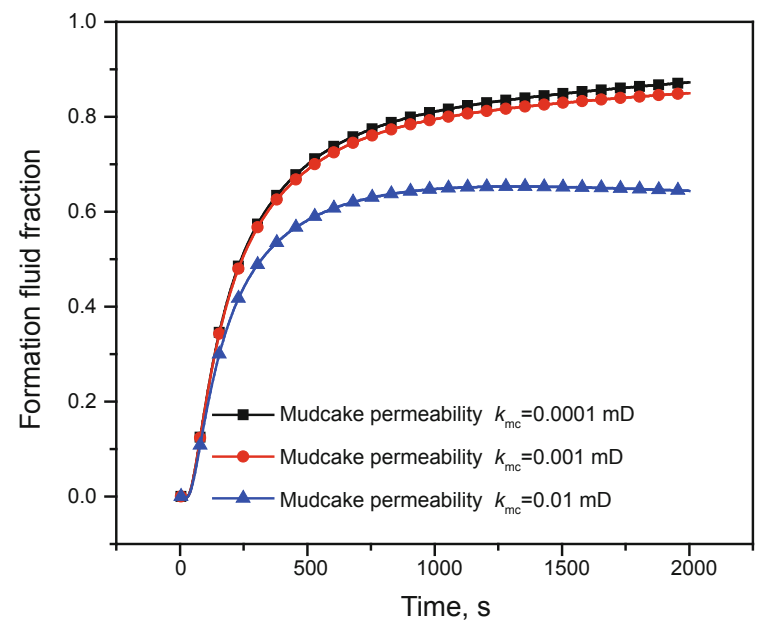

Fig. 6 The effect of mudcake permeability on fluid sampling

\section{Effect of mud filtrate invasion on pressure testing and fluid sampling}

When the FTWD operation starts, some mud filtrate has invaded into the formation to differing extents. To quantify the effect of filtrate invasion on pressure testing and fluid sampling, we developed a geometrical model (Fig. 7) and the model parameters are listed in Table 2.

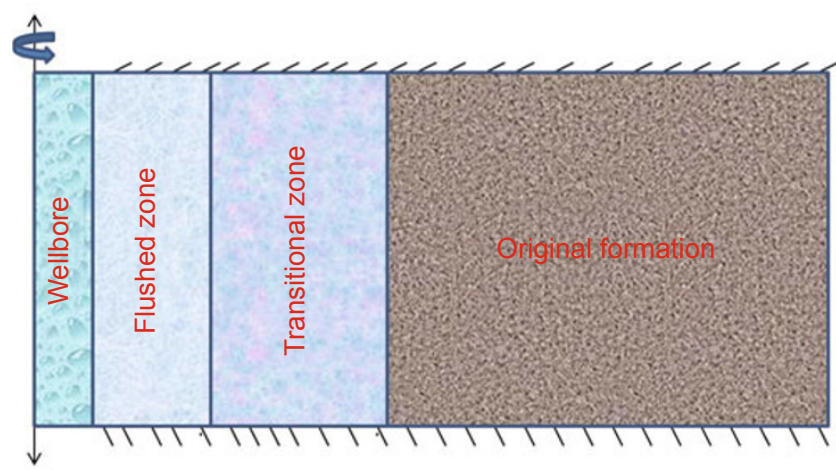

Fig. 7 Two-dimensional axisymmetric geometry for modeling filtrate invasion 
Table 2 Parameters for modeling the effect of filtrate invasion

\begin{tabular}{|c|c|c|c|c|c|}
\hline & $\begin{array}{c}\text { Permeability } \\
\mathrm{mD}\end{array}$ & $\begin{array}{l}\text { Pressure } \\
\text { psi }\end{array}$ & $\begin{array}{l}\text { Fluid density } \\
\qquad \mathrm{kg} / \mathrm{m}^{3}\end{array}$ & $\begin{array}{l}\text { Fluid viscosity } \\
\qquad \mathrm{mPa} \cdot \mathrm{s}\end{array}$ & $\begin{array}{c}\text { Compressibility } \\
\text { psi }^{-1}\end{array}$ \\
\hline Original formation & 10 & 5000 & 800 & 1.0 & $3 \times 10^{-6}$ \\
\hline Transitional zone & 8.0 & 5300 & 850 & 0.6 & $3 \times 10^{-6}$ \\
\hline Flushed zone & 5.0 & 5500 & 900 & 0.5 & $3 \times 10^{-6}$ \\
\hline
\end{tabular}

\subsection{Effect of filtrate invasion on pressure testing}

The impact of filtrate invasion depth on pressure testing in low permeability reservoirs was studied. The permeability valves of the original formation, transitional zone and the flushed zone were set at a constant of $0.1 \mathrm{mD}$ and the effect of filtrate invasion on reservoir permeability have not been considered. The other parameters are given in Table 2 . Simulation results (Fig. 8) show that the draw-down pressure declines most rapidly and then recovers to the original formation pressure $(5,000 \mathrm{psi})$ quickly when the filtrate invasion depth is $10 \mathrm{~cm}$. However, the pressure drawdown reduces significantly and the buildup pressure maintains above the original pressure for a long time when the invasion depth increases. The reason is that the pressure of the invasion zone is higher than the original formation and the supercharge pressure cannot be balanced in a short time. Therefore, the original formation pressure may not be able to be measured in the subsequent recovery process. In these cases, it is very difficult to measure the original formation pressure in low permeability reservoirs.

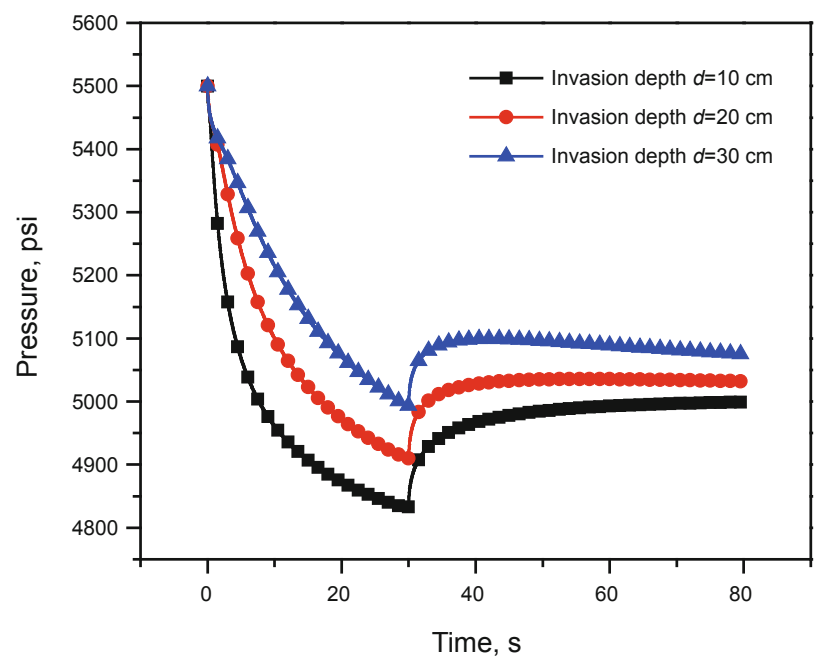

Fig. 8 The effect of mud filtrate invasion depth on pressure testing

Then we simulated the combined effect of invasion depth and change of formation permeability due to filtrate invasion. The permeability values of the original formation, transitional zone and the flushed zone were set at 10,8 and $5 \mathrm{mD}$, respectively. The simulation results in these cases are demonstrated in Fig. 9. As can be seen, the drawdown pressure declines more quickly as the invasion depth increases. This is may be due to formation damage caused by invasion of mud filtrate, hence the permeability of the formation near the wellbore decreases. In general, the deeper the mud invasion, the further the pressure drops. However, the pressure buildup has not changed much with different invasion depths. After 40 seconds all these curves buildup to the original formation pressure. This illustrates that the mud invasion has a slight effect on formation pressure measurements in a reservoir of moderate to high permeability.

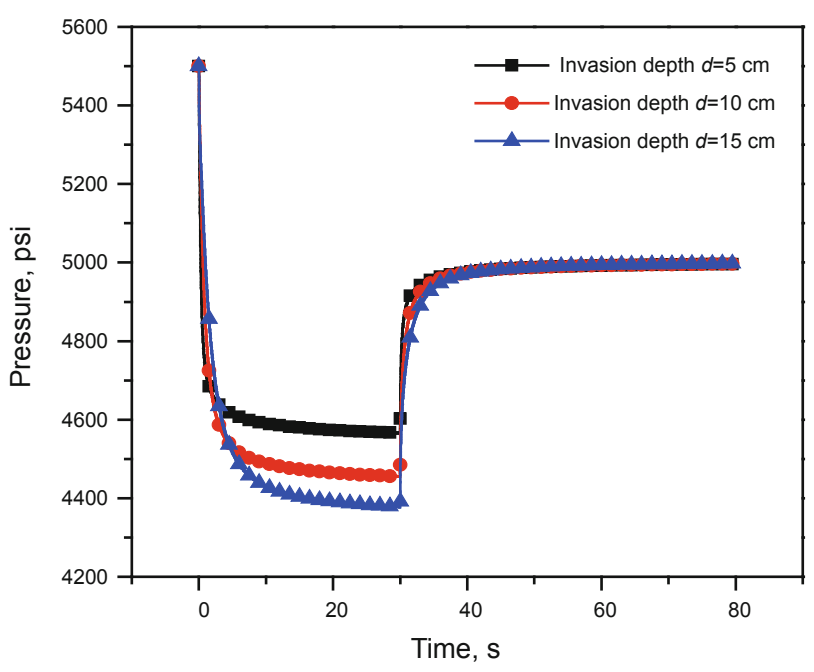

Fig. 9 The effect of mud filtrate invasion depth on pressure testing

\subsection{Effect of filtrate invasion on fluid sampling}

Finally, we studied the effect of invasion depth on fluid sampling. The initial conditions of the model were assumed as follows: the invaded zone near the wellbore is $100 \%$ saturated with mud filtrate, with a invasion depth of 10,15 and $25 \mathrm{~cm}$ in the radial direction, respectively. The mudcake completely isolates the drilling fluid from the formation and the formation permeability is $10 \mathrm{mD}$. A constant pump out rate is $15 \mathrm{~mL} / \mathrm{s}$. The simulation results are shown in Fig. 10. It can be seen from this figure, as the invasion depth increases, the sample quality degrades. This is due to more time being required to clean-up the filtrate in the longer mixing zone (travel distance). Compared to the WFT, the invasion depth is much shallower when FTWD starts fluid sampling. Therefore clean formation fluids can be obtained in a relatively short period of time.

\section{Field application of FTWD}

The field example presented here is taken from an oil field on Alaska's North Slope. The purpose of the field test was to probe the quality of the pressure testing while drilling and the ability to repeat testing at the same points. The Geo-Tap tool 


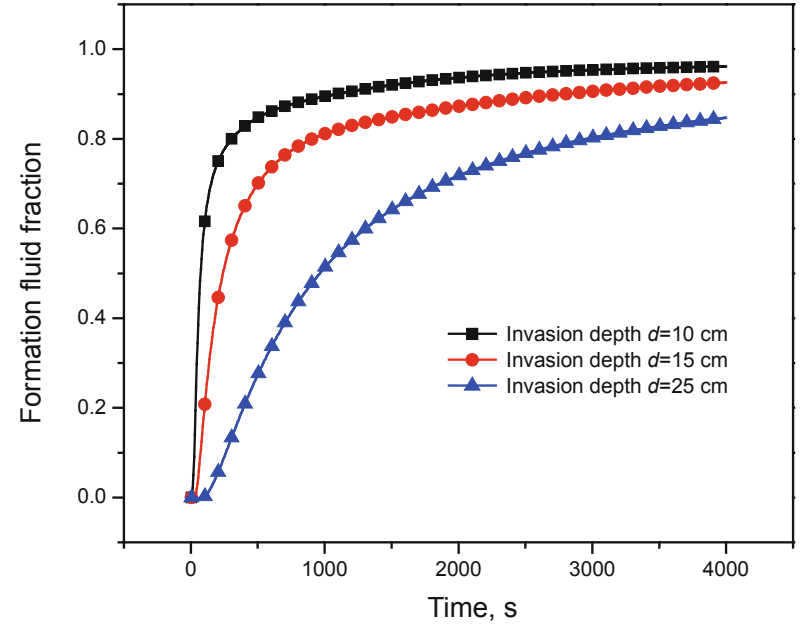

Fig. 10 The effect of filtrate invasion depth on fluid sampling

was set up with stabilizers for $97 / 8$ inches in the borehole in the pumps-off mode to avoid vibration from the mud motor on the bottom hole assembly. All the pressure points were selected by the BP geologist on location while drilling the reservoir section. These FTWD (Geo-Tap) data are shown in Figs. 11 through 13.

From Fig. 11, we can see that the LWD log data for the interval from 4,150 ft to 4,200 ft suggest a mixed sand/shale sequence with thin producing layers, and the interval from
4,260 $\mathrm{ft}$ to 4,290 $\mathrm{ft}$ is a sand reservoir. The eight test positions are located at the two layers. The locations were tested from PT\#1 to PT\#8 where the induction log indicated potential hydrocarbons. The results of these tests are also shown in Fig. 11 and summarized in Table 3. Tool malfunction occurred during PT\#2, so the formation pressure and drawdown permeability were not tested. PT\#5 and PT\#7 failed due to the probe being plugged. PT\#1 and PT\#8 were repeat tests at the same depth $(4,153 \mathrm{ft})$ and the time between the two tests was 24 hours. The measured pressures were within 11 psi, the difference between the two tests was relatively small and this level of repeatability is considered quite acceptable. The detailed pressure traces from both tests are shown in Fig. 12 and Fig. 13. However, the difference of pressure repeated in PT\#6 and PT\#7 was 21 psi at a depth of 4,289 ft, and the time interval was $20 \mathrm{~min}$, such result is not acceptable. This shows that the pressure at the location was not stable. The reason was that the reservoir permeability at this depth was very low (less than $1 \mathrm{mD}$ ) and therefore formation supercharging exited at a depth of 4,289 $\mathrm{ft}$ according to our studies. According to the above research results, Fig. 5 shows that the supercharge pressure over the original formation was more than $25 \mathrm{psi}$ when the formation permeability was $1 \mathrm{mD}$, therefore the pressure was found very different between the two repeated testing due to the formation permeability being less than 1 $\mathrm{mD}$, so the tested pressure was not the original pressure and the selected testing location was not appropriate.

Table 3 Modeling parameters

\begin{tabular}{cccccc}
\hline Test number & $\begin{array}{c}\text { True vertical depth(TVD) } \\
\mathrm{ft}\end{array}$ & $\begin{array}{c}\text { Hydrostatic pressure } \\
\mathrm{psi}\end{array}$ & $\begin{array}{c}\text { Formation pressure } \\
\text { psi }\end{array}$ & $\begin{array}{c}\text { Drawdown permeability } \\
\mathrm{mD}\end{array}$ & Comments \\
\hline PT\#1 & 4153 & 2037 & 1788 & 40 & Good test \\
PT\#2 & 4171 & 2052 & NA & NA & Tool malfunction \\
PT\#3 & 4171 & 2050 & 2018 & 16 & Good test \\
PT\#4 & 4182 & 2088 & 2044 & 10 & Good test \\
PT\#5 & 4267 & 2125 & NA & NA & Probe plugged \\
PT\#6 & 4289 & 2139 & 2101 & 0.8 & Good test \\
PT\#7 & 4289 & 2138 & 2080 & NA & Probe plugged \\
PT\#8 & 4153 & 2037 & 1799 & 42 & Good test \\
\hline
\end{tabular}

\section{Conclusions}

This paper analyzed the effect of the downhole dynamic environment on formation testing with an oil-water two phase finite element method. First, the paper investigated the influences of mudcake properties and formation on supercharging near the wellbore, and then investigated the influences of filtrate invasion on pressure testing and fluid sampling. Finally, the field example demonstrates the effect of downhole dynamic conditions on formation testing while drilling to support our simulations.

The simulations of formation supercharging show that the mudcake properties have significant influence on pressure testing and fluid sampling. The better the mudcake quality is, the weaker the formation supercharge pressure and the less time is required for fluid sampling, hence the better the quality of sampling. However, the mudcake quality is difficult to determine. It is related to formation permeability and mud invasion velocity. The simulations of pressure testing and fluid sampling show that the influence of mud filtrate invasion on a low permeability reservoir is significant. The deeper the mud invasion, the more difficult the formation pressure testing and fluid sampling becomes. In addition, the depth 


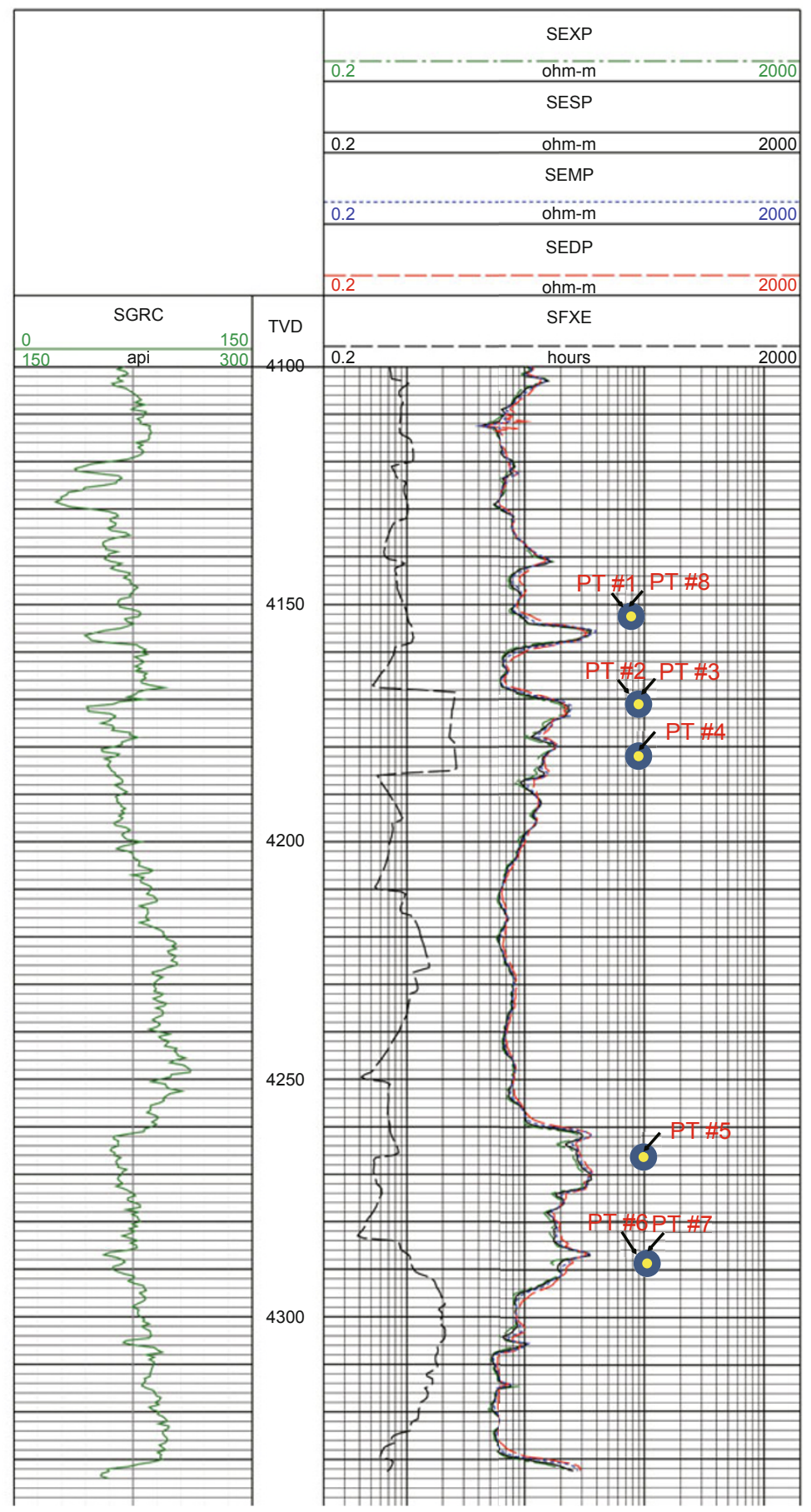

Fig. 11 LWD logs shown with Geo-Tap pressure test data for eight pressure tests Notice the repeatability of PT\#1 and PT\#8 (see Figs.12 and 13 and Table 3)

of mud invasion can be estimated by the electrical logging curves, so the selection of testing locations and pressure data processing should reference the geology information and logging data while drilling.

\section{Acknowledgements}

The authors would like to acknowledge those people whom we had the honor and pleasure to learn from and work with during our research. These people include, but are not limited to, YUE Wenzheng, WANG Hua, CHEN Ping, ZHANG Kuo and LI Junxiao from China University of Petroleum. Authors also thank BP and some staff involved in the Alaskan example used. This work was supported by the National Natural Science Foundation of China (No. 50674098), Major Project of Chinese Science and Technology (No. 2011ZX 05000-020-04) and Major Project of SINOPEC Science and Technology (No. P13147). 


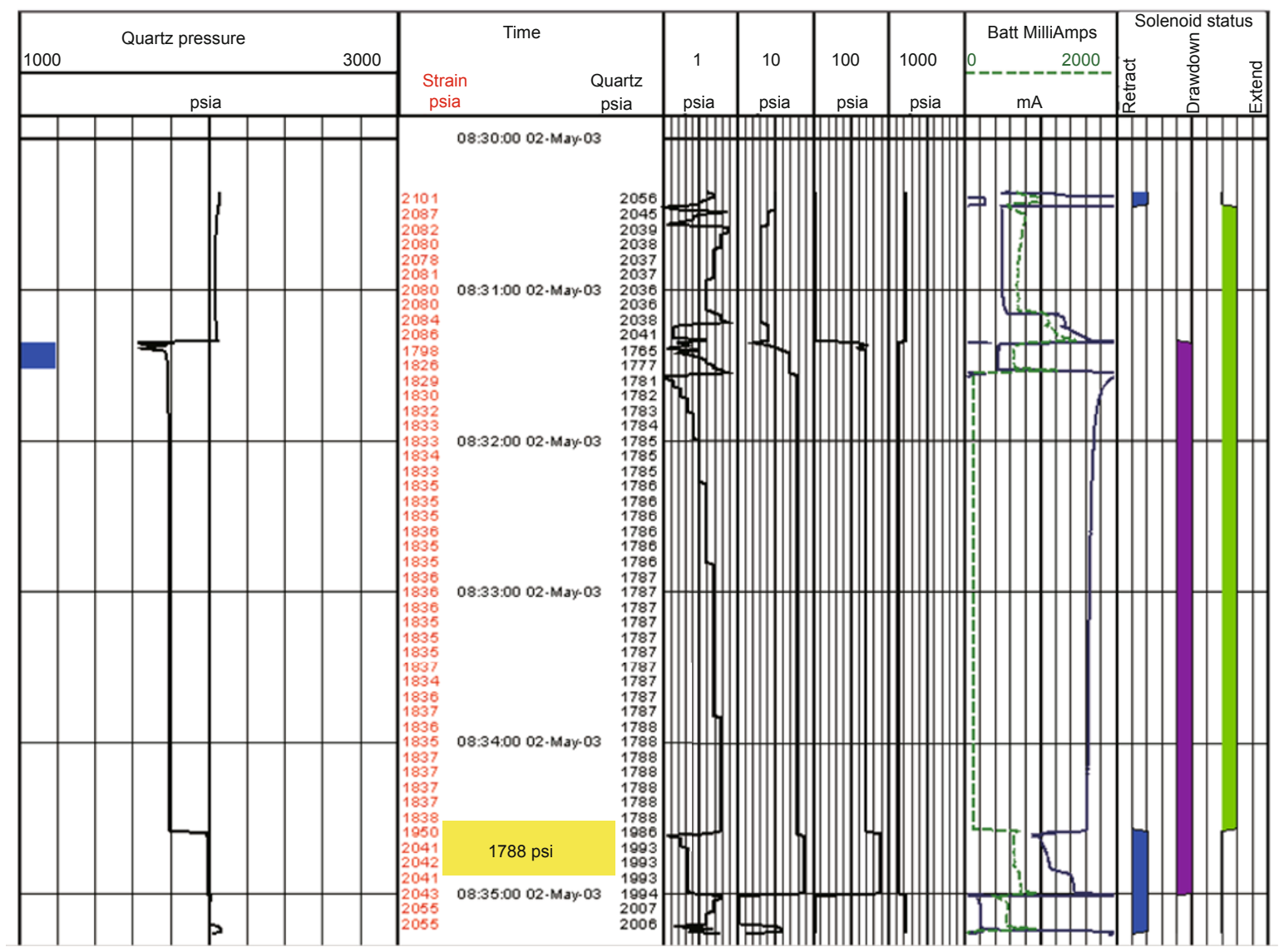

Fig. 12 Pretest PT\#1

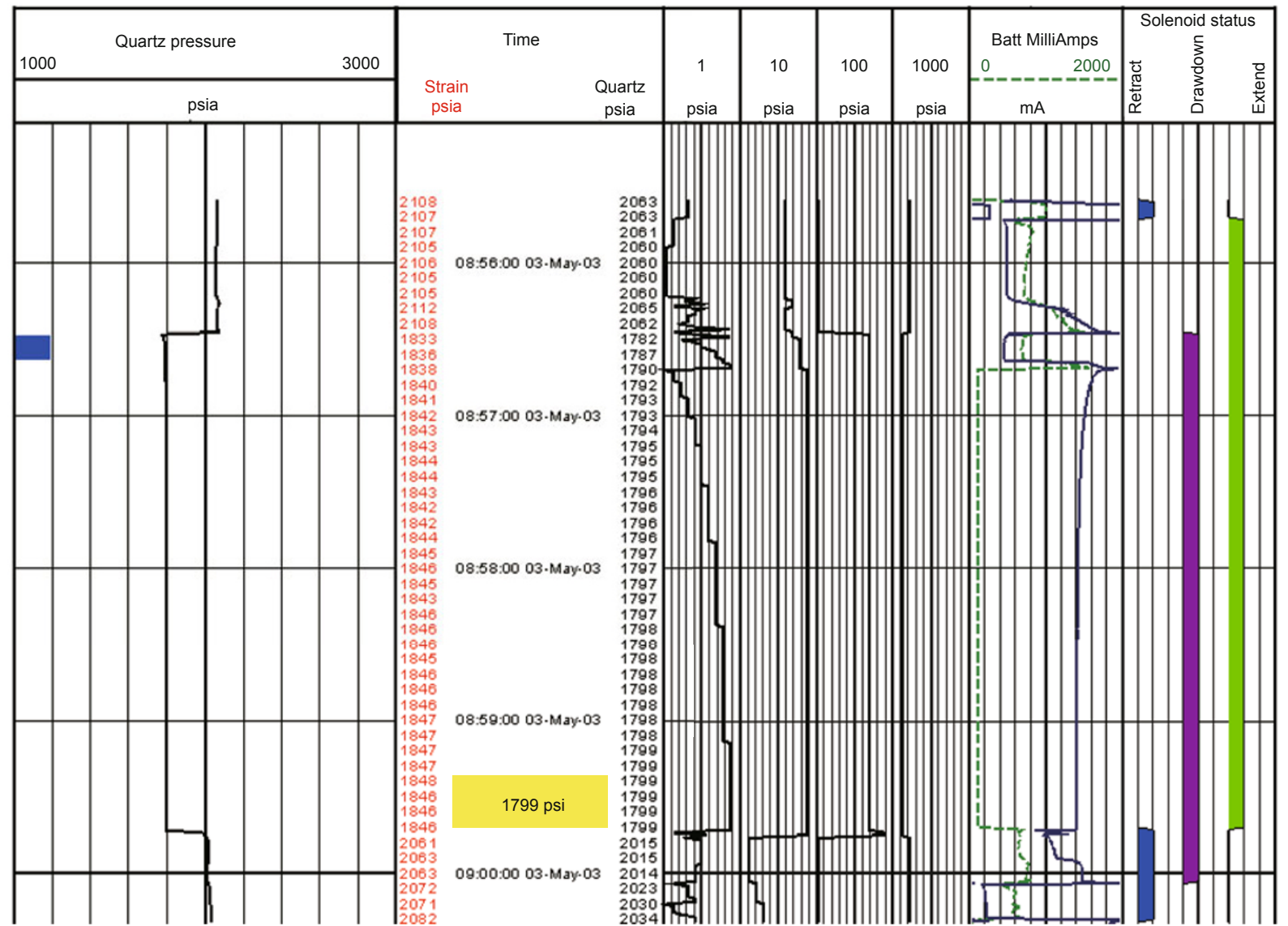

Fig. 13 Pretest $\mathrm{PT} \# 8$ 


\section{References}

Di D J, Tao G, Wang H, et al. Finite element simulation of wireline formation tester applied in fractured reservoir. The Open Petroleum Engineering Journal. 2012a. 5(1): 138-145

Di D J, Tao G, Sun H F, et al. Analysis and consideration of formation testing while drilling technology. Well Logging Technology. 2012b. 36(3): 294-299 (in Chinese)

Di D J, Tao G and Ye Q. Feasibility study on application of wireline formation testing to low permeability reservoirs. Progress in Geophysics. 2012c. 27(6): 2518-2525 (in Chinese)

Fey S, Fareed A, Mansur H, et al. Reducing the risks and costs of highly deviated and extended reach drilling through the application of formation pressure while drilling. Paper SPE 141487 presented at the SPE Europe/EAGE Annual Conference and Exhibition held in Vienna, Austria, 23-26 May 2011

Finneran J M, Green C, Roed H, et al. Formation tester while drilling experience in Caspian development projects. Paper SPE 967819 presented at the SPE Annual Technical Conference and Exhibition held in Dallas, Texas, USA, 9-12 October 2005

$\mathrm{Gu}$ N, Tao G and Liu S M. Responses of the wireline formation tester in permeability anisotropic formations. Chinese Journal of Geophysics. 2005a. 48(1): 229-234 (in Chinese)

Gu N, Tao G and Liu S M. The finite element simulation of wireline formation testing for oil-water two-phase flow. Progress in Geophysics. 2005b. 20(2): 337-341 (in Chinese)

Gu N, Tao G and Liu S M. Three-dimensional finite element modeling of oil-water two-phase profiles in the wireline formation test. Geophysics. 2007. (4): 429-435

Hou X R, Liu Y F and Hao L J. Formation pressure testing in dynamic drilling environments. Foreign Oilfield Engineering. 2005. 21(2): 13-18 (in Chinese)

Lee H, Proett M, Weintraub P, et al. Results of laboratory experiments to simulate the downhole environment of formation testing while drilling. SPWLA 45th Annual Logging Symposium, June 6-9, 2004

Lee $\mathrm{J}$ and Kasap E. Fluid sampling from damaged formations. Paper SPE 39817 presented at the 1998 SPE Permian Basin Oil and Gas Recovery Conference held in Midland, Texas, 25-27 March 1998

Li M G, Wan C G and Bai B Z. Present situation and application prospect of pressure survey while drilling. Fault-Block Oil \& Gas Field. 2008. 15(6): 123-126 (in Chinese)

Liu J L, Chen H N and Gao B T. Foreign measurement system for formation pressure while drilling and its application. Oil Drilling \& Production Technology. 2010. 32(1): 94-98 (in Chinese)

Masoud R, Gyllensten A, Amari, K, et al. Using formation-testing -while-drilling pressures optimize a Middle East carbonate reservoir drilling program. Paper SPE 120715 presented at the 2009 SPE Middle East Oil \& Gas Show and Conference held in the Bahrain International Exhibition Centre, Kingdom of Bahrain, 15-18 March 2009

Pop J, Laastad H and Eriksen K O. Operation aspects of formation pressure measurements while drilling. Paper SPE/IADC 92494 presented at the SPE/IADC Drilling Conference held in Amsterdam, The Netherlands, 23-25 February 2005

Proett M, Walker M, Welshans D, et al. Formation testing while drilling, a new era in formation testing. Paper SPE 84087 presented at the SPE Annual Technical Conference and Exhibition held in Denver, Colorado, USA, 5-8 October 2003

Proett M, Fogal J, Welshans D, et al. Formation pressure testing in the dynamic drilling environment. Paper SPE 87090 presented at the SPE Annual Technical Conference and Exhibition held in Dallas, Texas, USA, 2-4 March 2004

Proett M, Welshans D, Sherrill K, et al. Formation testing goes back to the future. SPWLA 51th Annual Logging Symposium held in Perth, Australia, 19-23 June 2010

Proett M, Eyuboglu S, Wilson J, et al. New sampling and testing-whiledrilling technology, a safe, cost-effective alternative. Paper SPE/ IADC 140337 presented at the SPE/IADC Drilling Conference and Exhibition held in Amsterdam, The Netherlands, 1-3 March 2011

Ren F G and Ma J G. Technique of formation pressure testing while drilling and its application. Well Logging Technology. 2005. 29(4): 385-387 (in Chinese)

Sarkar A K, Lee J and Kasap E. Adverse effect of poor mudcake quality: a supercharging and fluid sampling study. Paper SPE 48958 presented at the 1998 SPE Annual Technical Conference and Exhibition held in New Orleans, Louisiana, 27-30 September 1998

Seifert D J, Al-Dossari S, Burinda B J, et al. Application for formation testing while drilling in the Middle East. Paper SPE 93392 presented at the 14 SPE Middle East Oil \& Gas Show and Conference held in Bahrain International Exhibition Centre, Bahrain, 12-15 March 2005

Su Y N and Dou X R. MWD \& LWD and logging tools. Oil Drilling \& Production Technology. 2005. 27(1): $74-78$ (in Chinese)

Wang H, Tao G and Zhang X J. Review on the development of sonic logging while drilling. Well Logging Technology. 2009. 33(3): 197203 (in Chinese)

Yang L and Tian S B. New style tool of pressure tester while drilling. Foreign Oil Field Engineering. 2005. 21(11): 20-23 (in Chinese)

Yi S G, Wu X L and Jin Z W. A study of numerical simulation of pressure response of wireline formation tester. Well Logging Technology. 1997. 21(5): 16-20 (in Chinese)

Zhang X Y, Guo Y J and Wang J N. The logging while drilling: past, present and future. Well Logging Technology. 2006. 30(6): 487-492 (in Chinese)

Zhao Z X, Han Y, Gao X, et al. SDC-I pressure tester while drilling. China Petroleum Machinery. 2011. 39(2): 52-54 (in Chinese)

Zhou B, Tao G and Diao S. Approximate analytic solution to pressure of the wireline formation tester considering flow line storage effect. Well Logging Technology. 2003. 25(1): 27-29 (in Chinese)

Zhou B, Mo X W and Tao G. The numerical simulation of wireline formation tester with finite element method. Journal of Jilin University: Earth Science Edition. 2007. 37(3): 629-632 (in Chinese)

(Edited by Sun Yanhua) 